\title{
CAUSES OF LOW VISION AND ANALYSIS OF ACCEPTANCE OF LOW VISION AIDS IN STUDENTS ATTENDING THE SCHOOLS FOR BLIND IN MEERUT, WESTERN UTTAR PRADESH
}

\author{
Kritika Gogia1, Jaishree Dwivedi², Sandeep Mithal ${ }^{3}$, Alka Gupta ${ }^{4}$, Lokesh Kr. Singh ${ }^{5}$
}

${ }_{1}^{1}$ Postgraduate Student, Department of Ophthalmology, LLRM Medical College, Meerut, Uttar Pradesh. ${ }^{2}$ Assistant Professor, Department of Ophthalmology, LLRM Medical College, Meerut, Uttar Pradesh. 3 Professor, Department of Ophthalmology, LLRM Medical College, Meerut, Uttar Pradesh. ${ }_{4}^{4}$ Associate Professor, Department of Ophthalmology, LLRM Medical College, Meerut, Uttar Pradesh. ${ }_{5}^{5}$ Assistant Professor, Department of Ophthalmology, LLRM Medical College, Meerut, Uttar Pradesh.

\section{ABSTRACT}

\section{BACKGROUND}

Low vision and blindness are a growing health problems that adversely affect the quality of life of an individual. Currently, India is home to around one-third to one-fourth of the world's blind population and childhood blindness makes a significant contribution to this. ${ }^{1}$

\section{MATERIALS AND METHODS}

The study was conducted in the Upgraded Department of Ophthalmology in LLRM Medical College, Meerut from July 2016 to June 2017. The study was done to survey the causes of low vision in students attending Blind Schools in Meerut, Western UP, to find out the percentage of preventable blindness amongst these students and to assess the acceptance of low vision aids in these students. In this study, 55 students of age group aged 5 to 18 yrs. with best Corrected Visual Acuity $<=6 / 18$ (Snellen's chart) were included. The causes of low vision were identified. For each child the need of optical, medical or surgical interventions was recorded. The acceptance of low vision aids was analysed.

\section{RESULTS}

Congenital ocular anomalies (mainly microphthalmos, anophthalmos, coloboma etc.) accounted for 55.45\% of low vision. Corneal pathologies (20.90\%) were the second most common cause of blindness. Treatable causes included cataract, glaucoma and amblyopia accounting for $14.54 \%$.

\section{CONCLUSION}

Globe anomalies (40\%) were found to be the most predominant anatomical cause of blindness in students followed by corneal pathologies (20.90\%), retinal anomalies (12.72\%), optic nerve pathology (11.81\%), lens anomalies (7.27\%) and uveal anomalies (3.63\%). A total of $14.54 \%$ of eyes had treatable causes of low vision which included amblyopia, congenital glaucoma, cataract and pathological myopia. Almost, $32.72 \%$ of the students had preventable or treatable causes indicating the need of specific public health strategies.

\section{KEYWORDS}

Blindness, Low Vision, Amblyopia, Microphthalmos, Corneal Pathology, Anophthalmos, Congenital Glaucoma.

HOW TO CITE THIS ARTICLE: Gogia K, Dwivedi J, Mithal S, et al. Causes of low vision and analysis of acceptance of low vision aids in students attending the schools for blind in Meerut, Western Uttar Pradesh. J. Evolution Med. Dent. Sci. 2018;7(14):1703-1704, DOI: $10.14260 /$ jemds/2018/385

\section{BACKGROUND}

Childhood blindness is one of the priorities in vision 2020; the right to sight. It is estimated that there are 1.4 million blind children in the world, two-thirds of whom live in the developing countries. ${ }^{2}$

Low vision ${ }^{3}$ is a leading cause of disability requiring aids in activities of daily living. Chronic disabling, non-reversible, surgically with conventional refraction are collectively known as low vision.

'Financial or Other Competing Interest': None.

Submission 06-02-2018, Peer Review 15-03-2018,

Acceptance 22-03-2018, Published 02-04-2018.

Corresponding Author:

Dr. Jaishree Dwivedi,

\#112-A, Ansal Town,

Modipuram Bypass,

Meerut, Uttar Pradesh.

E-mail: drjaishreedwivedi@gmail.com

DOI: $10.14260 /$ jemds/2018/385
The WHO, working definition of low vision (WHO, 1992) is as follows: A person with low vision is one who has impairment of visual functioning even after treatment and/or standard refractive correction, and has a visual acuity of less than 6/18 to light perception or a visual field of less than 10 degrees from the point of fixation, but who uses or is potentially able to use, vision of the planning and/or execution of a task. ${ }^{4,5}$

Low vision rehabilitation is the process of restoring functional ability and improving quality of life and independence of patient with low vision. ${ }^{6}$ Low vision aids for near and distance.

\section{Aims and Objectives}

1. To survey the causes of low vision in the students attending blind schools in Meerut, Western UP.

2. To find out the percentage of preventable blindness amongst these students.

3. To assess the acceptance of low vision aids in these students. 


\section{MATERIALS AND METHODS}

- The study was conducted in the upgraded Dept. of Ophthalmology, LLRM, Meerut from July 2016 to May 2017.

- $\quad$ Study Design- Descriptive, Cross-Sectional study.

- Three blind schools of Meerut were included in the study.

- The children were examined in their respective school premises.

- Demographic details, medical and family history of each child was recorded.

- Visual acuity was assessed in each eye using a LogMAR visual acuity test chart.

- Near vision was assessed using figures equivalent to N.

- Anterior segment of the eye was examined using a torch light/ slit lamp. The posterior segment was examined using direct and indirect ophthalmoscope after dilatation of pupil. The cause of low vision was identified. Cycloplegic refraction was done. For each child, the acceptance of low vision aids was analysed and the visual prognosis was assessed.

\section{Inclusion Criteria}

- $\quad$ Students in the age group of $5-18$ yrs.

- Best corrected visual acuity $</=0.50$ LogMAR.

\section{Exclusion Criteria}

- Mentally challenged children.

\section{RESULTS}

A total of 110 eyes of 55 students were examined, out of which $49(89.10 \%)$ were males and $6(10.90 \%)$ were females.

Globe anomalies (40\%) were found to be the most predominant anatomical cause of blindness in students followed by corneal pathologies (20.90\%), retinal anomalies $(12.72 \%)$, optic nerve pathology $(11.81 \%)$, lens anomalies $(7.2 \%)$ and uveal anomalies $(3.63 \%)$.

Most cases of corneal scarring were attributed to infections and nutritional deficiencies in infancy and were preventable conditions. Almost, $18.18 \%$ of the total eyes had preventable cause of low vision. A total of $14.54 \%$ of eyes had treatable causes of low vision which included amblyopia, congenital glaucoma, cataract and pathological myopia.

Congenital anomalies (55.45\%) were the most common causes of low vision in the students.

Of the total 110 eyes, $12.72 \%$ had low vision due to hereditary causes.

$15.45 \%$ of eyes accepted low vision aids for distance and $16.36 \%$ for near.

\section{DISCUSSION}

In the present study congenital ocular anomalies (mainly microphthalmos, anophthalmos, coloboma etc.) accounted for $55.45 \%$ low vision. ${ }^{7}$

Krishnaiah $\mathrm{S}$ et al conducted a similar study in a coastal district of Andhra Pradesh in South India and found that congenital anomalies $(41.4 \%)$ were the most common cause of blindness. ${ }^{8}$
In a study conducted by Titiyal JS et al, $42.3 \%$ of the children had congenital ocular anomalies and they accounted for the most cause of visual impairment. ${ }^{9}$

Corneal pathologies were the second most common cause of blindness and the major preventable cause identified. Although, it is difficult to specifically ascertain the aetiology of corneal scarring several years after the original pathology, Vitamin A deficiency appears to be the major cause as in the majority of children with corneal scarring, diarrhoea or measles (which can precipitate acute Vitamin A deficiency) preceded the onset of visual loss. ${ }^{10}$

\section{CONCLUSION}

In this study, $32.72 \%$ of children were blind from preventable or treatable conditions. These findings suggest the importance of public health strategies, primary prevention for example high measles immunisation coverage, promotion of breastfeeding, health and nutrition education, and continued programs for the control of Vitamin A deficiency through child survival programs.

Treatable causes included cataract, glaucoma and amblyopia. There is a need to expand specialist paediatric ophthalmic services in India, and it has been recommended that there should be one well-equipped child eye care centre for every 10 million total population. There is a need for early detection of cataract and glaucoma with appropriate referral to a tertiary eye care centre.

\section{REFERENCES}

[1] World Health Organization. Global initiative for the elimination of avoidable blindness. WHO/PBL/97.61. Geneva: WHO, 1997.

[2] World Health Organization. Preventing blindness in children. Report of a WHO/IAPB scientific meeting. WHO/PBL/00.71. Geneva: WHO, 2000.

[3] Anon. Blindness in the world. Surv Ophthalmol 2000;45(Suppl):S21-S31.

[4] Census of India 2001. India: Registrar General and Census Commissioner, 2001.

[5] American Academy of Ophthalmology. Clinical Optics 2009-2010.

[6] Sterns GK, Hyvarinen L. Adressing pediatric issues. In: Fletcher DC, edr. Low vision rehabilitation: caring for the whole person. American Academy of Ophthalmology 1999: p. 107-19.

[7] Faye EE. Clinical low vision. $2^{\text {nd }}$ edn. Boston/Toronto: Little, Brown and Company 1984.

[8] Watson GR. Using low vision effectively. In: Fletcher DC, edr. Low vision rehabilitation: caring for the whole person. American Academy of Ophthalmology 1999: p. 61-87.

[9] Hyvarinen L, Jacob N. What and how does this child see? Assessment of visual functioning for development and learning. Helsinki, Finland: Vistest Ltd., 2011: p. 174.

[10] Sia DI, Muecke J, Hammerton M, et al. A survey of visual impairment and blindness in children attending four schools for the blind in Cambodia. Ophthalmic Epidemiol 2010;17(4):225-33. 